\title{
Las raíces de la felicidad, según la mística dominicana (el Maestro Eckhart y Enrique Suso)*
}

\author{
Silvia Bara Bancel**
}

Recibido: 11 de agosto de 2015 • Aprobado: 20 de septiembre de 2015

\section{Resumen}

La llamada "mística renana" -designación frecuente en ámbitos francófonos- o "mística alemana", más propiamente debería designarse como "mística dominicana"; pues se trata de la escuela de pensamiento y de espiritualidad que surge y se desarrolla en la provincia dominicana de Teutonia, en el siglo XIV (provincia religiosa que se extendía por Teutonia, con una extensión mucho mayor que la Alemania actual), y cuyos principales representantes son el Maestro Eckhart, Enrique Suso o Susón y Juan Tauler, todos ellos frailes dominicos.

Palabras clave: mística, mística renana, felicidad, Eckhart, Suso.

* Artículo resultado de la investigación de la autora y socializado con la Facultad de Teología. DOI: http://dx.doi.org/10.15332/s2011-9771.2016.0001.01

** Doctora en Teología. Docente de la Facultad de Teología y colaboradora del servicio Pastoral de la Universidad Pontificia Comillas de Madrid, España. Correo electrónico: Ssbara@ teo.upcomillas.es 


\title{
The roots of happiness, according to dominican mystics Master Eckhart and Enrique Suso
}

\begin{abstract}
The "Rhineland mysticism" -name frequently used in Francophone circles- or "German mysticism", should more appropriately be called "Dominican mysticism"; since it is the school of thinking and spirituality that emerged and developed in the Dominican province of Teutonia, in the fourteenth century (religious province that extended through Teutonia, with an extent much larger than todays' Germany), and whose main representatives are Meister Eckhart, Henry Suso or Seuse and Johannes Tauler, all of them Dominican friars
\end{abstract}

Keywords: Mysticism, Rhineland mysticism, happiness, Eckhart, Suso.

\section{Les racines du bonheur, d'après la mystique dominicaine Maître Eckhart et Enrique Suso}

\section{Résumé}

La dénommée "mystique rhénane "- appellation fréquente dans les domaines francophones- ou "mystique allemande", devrait se désigner plus précisément "mystique dominicaine"; car il s'agit de l'école de pensée et de spiritualité qui surgit et se développe dans la province dominicaine de Teutonia, au XIV siècle (province religieuse qui s'étendait par la Teutonia, avec une étendue beaucoup plus ample que l'Allemagne actuelle), et dont les principaux représentants son Maître Eckhart, Enrique Suso o Susón et Juan Tauler qui étaient tous des moines dominicains.

Mots-clés: Mystique, mystique rhénane, bonheur, Eckhart, Suso. 


\section{Introducción}

\section{Los místicos alemanes}

Asumiremos el planteamiento del gran especialista español, Juan Martín Velasco, en su estudio comparado del fenómeno místico, donde se afirma: “Con la palabra 'mística' nos referimos a experiencias interiores, inmediatas, fruitivas, que tienen lugar en un nivel de conciencia que supera la que rige en la experiencia ordinaria y objetiva, [experiencias] de la unión -cualquiera que sea la forma en que se la viva- del fondo del sujeto con el todo, el universo, el absoluto, lo divino, Dios o el Espíritu [...]." (Martín, 1999).

Así pues, la mística no es sino la vivencia de la actitud creyente en toda su intensidad. En este sentido denominamos místicos al Maestro Eckhart y sus discípulos: no porque padecieran fenómenos extraordinarios, como levitaciones o desmayos y arrobamientos; sino porque aluden a una experiencia: la del encuentro y la unión con Dios, que dinamiza toda su predicación, su estudio y su reflexión filosófica y teológica. Ellos la entienden como un saber teóricopráctico, sin divorcio entre razón y fe o entre teología dogmática y espiritualidad o experiencia creyente. Así, el Maestro Eckhart era designado en su tiempo no solo como Maestro o catedrático de Universidad (Lehremeister), sino también, y sobre todo, como maestro de vida (Lebenmeister). Y según una visión alegórica de Enrique Suso en su Horologium Sapientie, en la Escuela de Teología, «la maestra es la eterna Sabiduría, lo que se enseña es la verdad y el fin de la Teología es [alcanzar] la felicidad eterna». (Hor. II c.1, 520: 27-28). Así pues, Suso y sus hermanos consideraban que la meta de la Teología, y de toda vida humana, es la felicidad.

\section{¿Felicidad?}

Cabe plantear la pregunta ¿qué entendemos por felicidad? La historia de la filosofía, y más recientemente, la psicología, son testigos de los diversos caminos propuestos para alcanzarla. Unos entienden la felicidad como disfrute, como placer (hedonismo); muchos buscan felicidad en la adquisición de bienes materiales, o en el reconocimiento y prestigio social; otros entienden la felicidad como satisfacción por el deber cumplido, por la coherencia con unos valores; hay quien pone su felicidad en sus relaciones interpersonales positivas: en el amor, la amistad, la 
familia; o en contar con un sentido en la vida; otros consideran la felicidad como la realización plena de nuestro ser (eudemonismo); etc.

La pregunta por la felicidad sigue manteniendo toda su vigencia. Los últimos estudios sociológicos, que cuantifican el sentimiento de felicidad y bienestar general de la población de un país, muestran; por ejemplo, que una vez alcanzados unos niveles básicos de bienestar, el sentimiento de felicidad no corresponde directamente con la renta per cápita, y más dinero no produce más felicidad (resultado que sorprende a algunos analistas, pero desde una perspectiva humanista cristiana no tiene nada de extraño). Así, por ejemplo, según el informe World Happiness Report, en 2014 Colombia ocupaba el puesto 33 en el Ranking de países más felices del mundo, por delante de España, en el puesto 36, y de países del sudeste asiático como Japón, en el puesto 46 del ranking. (El país cuyos habitantes se sienten más felices en el mundo, si tienen curiosidad por conocerlo, es Suiza y, de América Latina, Costa Rica figura en el puesto 12 del ranking mundial de felicidad). (theglobeandmail, s. f.).

Volviendo a los místicos alemanes, estos coincidirían seguramente con José Luis Martín Descalzo, sacerdote, periodista y escritor español del siglo XX, que sostenía lo siguiente:

«Los humanos no nacemos felices ni infelices, sino que aprendemos a ser una cosa u otra y, en una gran parte, depende de nuestra elección el que nos llegue la felicidad o la desgracia. [...] No es cierto, como muchos piensan, que la dicha pueda encontrarse como se encuentra por la calle una moneda o que pueda tocar como una lotería, sino que es algo que se construye, ladrillo a ladrillo, como una casa» (Martín, 2014).

Sí, todos podemos ser felices. Es más, todos somos llamados a serlo y a vivir en plenitud, y a reconocer que la felicidad es posible "ya ahora", en este momento, en el presente, aunque nuestra situación no responda a nuestras expectativas o nuestros sueños. ¿En qué consiste, entonces, la felicidad?

\section{La felicidad plena, fin último del ser humano}

\section{a. ¿En qué consiste, entonces, la felicidad?}

Para el Maestro Eckhart y sus discípulos, la felicidad plena; es decir, la bienaventuranza, no se halla sino en el «ser uno con Dios», «gustar a Dios», y llegar a 
«experimentarle» o "padecerle», en expresión de influencia dionisiana ${ }^{1}$. Por ello, todas sus obras y, en especial, sus sermones están orientados a un mismo objetivo: invitar y proponer esta experiencia de Dios, origen y fin último del ser humano. Así, Eckhart afirma en el sermón 101:

«De la verdadera unión depende toda la bienaventuranza [del ser humano]. [...] Dios es su felicidad suprema y el fin último, y pertenece a la naturaleza de Dios ser comienzo y fin de todas las cosas. Ninguna criatura puede ser tu felicidad, ninguna tu perfección [sino solo Dios]» (Ekhard, 2008) $)^{2}$.

Y Suso lo recuerda de diversas maneras: «La bienaventuranza -explica- consiste en gozar plenamente de Dios, de modo que toda mediación y toda alteridad son suprimidas» (Bihlmeyer \& Seuse, 1961) ${ }^{3}$. Y de manera poética, pone en boca de Dios la siguiente afirmación:

«زFeliz aquél que participe por toda la eternidad del juego del amor, de la danza de la alegría a mi lado, en la delicia del cielo, conducido por mi mano admirable, en una alegre seguridad!» (Suso, s. f.) ${ }^{4}$.

1 Retomamos y ampliamos las reflexiones sobre esta cuestión publicadas en Silvia BARA BANCEL, Las raíces de la felicidad, según el Maestro Eckhart, (Sáncho, 2008, pp. 113-114).

2 Nos servimos de los originales en alto alemán medio. Para los tratados y los sermones 1-86 del Maestro Eckhart emplearemos la siguiente edición bilingüe: MEISTER ECKHART, Werke. I Predigten. Text und Kommentar; II. Predigten, Traktate. Text und Kommentar, ed. Niklaus LARGIER (Deutscher Klassiker Verlag TB 24-25), Frankfurt a. M. 2008 (en adelante Largier, volumen y página). Los sermones eckhartianos 86-105 han sido publicados únicamente en la edición crítica, MEISTER ECKHART, Die deutschen und lateinischen Werke. Die deutschen Werke IV,1, ed. Georg STEER, Kohlhammer, Stuttgart 2003 (en adelante DW IV y página). La obra latina de Eckhart se citará igualmente según la edición crítica, Die deutschen und lateinischen Werke. Die lateinischen Werke, 5. vol., ed. de Joseph KOCH et al., Kohlhammer, Stuttgart 1956ss (en adelante LW, volumen y página). La versión castellana de los textos es nuestra, a no ser que indiquemos la fuente entre paréntesis. Los tratados y sermones 1-59 han sido traducidos por Ilse M. de Brugger y publicados en MAESTRO ECKHART, Obras alemanas: Tratados y Sermones, Barcelona 1983. Reedición: Las Cuarenta, Buenos Aires, 2013 (citado como Brugger y página). Y una selección de textos eckhartianos se encuentra en MAESTRO ECKHART, El fruto de la nada, ed. de Amador VEGA ESQUERRA, Alianza Editorial, Madrid 2011 (citado como Vega y página). Aquí: Eckhart, Sermón 101 Dum medium silentium, DW IV, 352.

3 Citaremos la obra de Suso a partir de su edición crítica: Karl BIHLMEYER (ed.), HEINRICH SEUSE. Deutsche Schriften, Kohlhammer, Stuttgart 1907 (Reimpresión: Minerva, Frankfurt a. M. 1961), indicando el libro, capítulo y página. Aquí: Libro de la Verdad (Daz buechli der warheit) c.4, 334. En adelante, todas las traducciones de las citas de Suso son nuestras.

4 Suso, Libro de la Sabiduría eterna (Daz buechli der ewigen wisheit) c.7, 225:1-3. 
Por tanto, según los místicos alemanes, «nuestra felicidad no depende de nuestras acciones, $\neg-$ ni tampoco de nuestros sentimientos, o de nuestra situación concreta- sino, por el contrario, reside en que "experimentemos" o "padezcamos" a Dios (got lîden)» (Ekhart, s. f.) $)^{5}$.

Con frecuencia, designan esta experiencia como un nacimiento, un renacimiento o alumbramiento, "el nacimiento de Dios en nosotros". El Maestro Eckhart lo explica así en un sermón:

"“Dios ha enviado a su Hijo unigénito al mundo"; esto no debéis entenderlo [únicamente] en referencia al mundo exterior, cuando Cristo comía y bebía con nosotros, sino con relación al mundo interior. De la misma manera verdadera en que el Padre engendró de forma natural al Hijo [...], igualmente lo engendra en lo más íntimo del espíritu [humano], y ése es el mundo interior» (Ekhart, s. f. $)^{6}$.

Y en otro sermón añade además:

«La mayor bienaventuranza, [la mayor felicidad del ser humano], es que Dios pueda nacer y manifestarse en el alma por una unión espiritual. [...] El nacimiento interior de Dios en el alma es la realización suprema de toda bienaventuranza» (Ekhart, s. f. $)^{7}$.

\section{b. «Ya» (aunque «todavía no» en plenitud)}

Esta felicidad, esta bienaventuranza -sostiene Eckhart-, se ha de buscar ya en esta vida. Pues el Maestro alemán está convencido de que es posible «probar a Dios» (Ekhart, s. f. $)^{8}$, saborearle, hacer experiencia de Dios "ahora", en el presente. -Seguramente él mismo tuvo una experiencia mística, aunque nunca se expresa en primera persona, a diferencia de su discípulo Suso-. Según Eckhart, en esa experiencia de nacimiento o de ser «uno» con Dios, don de la gracia, «la vida eterna» irrumpe en cierto modo en el tiempo.

5 Eckhart, Sermón 102 Ubi est qui natus est, DW IV, 422.

6 Eckhart, Sermón 5b, Vega, 49.

7 Eckhart, Sermón 87, DW IV, 27 (nuestra traducción).

8 Cf. Eckhart, Sermón 73 Dilectus deo et hominibus, Largier II, 92. «...pues ellos [las personas buenas] han probado (gesmecket) a Dios». 
Al final del sermón 24, explica que la expresión «plenitud del tiempo» (volheit der zît) tiene dos sentidos: uno, como punto final, cuando algo se acaba, y otro, como fin último, como meta, como «eternidad». Aludiendo a este segundo sentido, afirma:

«[...] es la eternidad, porque entonces el tiempo termina, pues allí no hay ni antes ni después. Allí todo se halla presente y es nuevo, y allí abarcas, en una contemplación presente, aquello que fue y que en cualquier momento será. Allí no hay antes ni después, allí todo está presente» (Ekhart, s. f.) $)^{9}$.

Por lo tanto, la noción de «vida bienaventurada»-accesible ya en esta vida, aunque no en plenitud-, está en el centro del proyecto teológico de Eckhart, que integra el ideal filosófico de felicidad intelectual predicado por los maestros aristotélicos de la segunda mitad del siglo XIII. Frente a una concepción que reduce la bienaventuranza a la visión beatífica, tras el Juicio final -la del papa Juan XXII, por ejemplo-, Eckhart-y más tarde sus discípulos- propone una bienaventuranza in via, la felicidad del «hombre noble», o mejor dicho, «el ser humano (mensch) noble», es decir, la persona realizada, feliz, a la que llama también «persona interior», o «nueva», «justa», «pobre» o «simple». La persona «noble» es aquella que sigue el sermón de la Montaña y se sienta, con Cristo, en las «cimas de la contemplación» (De Libera, 1999, p. 37).

\section{c. Para todos, por la «nobleza» del alma, imagen de Dios}

Y esta invitación a la felicidad es "para todos», pues tiene su origen en el inmenso amor de Dios y de su proyecto de salvación. Así por ejemplo, exclama en el sermón 69:

«Sabed que Dios ama tan poderosamente al alma que es una maravilla. El que privara a Dios de amar al alma lo privaría de su vida y de su ser, o mataría a Dios, si pudiéramos hablar así, pues el mismo amor con el que Dios ama al alma es su vida, y en este mismo amor el Espíritu Santo florece, y este mismo amor es el Espíritu Santo. Y como Dios ama

9 Eckhart, Sermón 24 Sant Paulus sprichet, Largier I, 280-282. 
tan poderosamente al alma, el alma ha de ser también algo grande» (Ekhart, s. f. $)^{10}$.

¿En qué consiste, según Eckhart, la grandeza del alma humana? En que ha sido creada capaz de Dios y receptiva. Por amor, Dios ha creado al ser humano a su imagen y semejanza, con «una gran nobleza» en su naturaleza, -dice Eckhart-, y por gracia puede llegar a ser «divinizado» ${ }^{11}$, tal y como ya afirmaban los Padres Griegos (Ireneo, Orígenes, el Pseudo-Dionisio, Máximo el Confesor...).

Junto con Agustín y la tradición anterior, Eckhart considera que la imagen de Dios se concentra especialmente en el «intelecto», pues Dios es también Intelecto (Ekhart, s. f.) $)^{12}$.

Sin embargo, se ha de entender bien esta cuestión, pues para Eckhart y su escuela, el Intelecto humano es mucho más que la capacidad de abstracción a partir de los sentidos y está más vinculado a la noción plotiniana del nous: es la parte más íntima y más elevada del ser humano, que le capacita para recibir a $\operatorname{Dios}^{13}$. Además parece participar de la teoría del conocimiento de Alberto Magno, que considera que el Intelecto está iluminado directamente por la luz divina.

Por otra parte, además de «intelecto», «razón superior», o el «intelecto paciente», el Maestro Eckhart se refiere a esta receptividad en la que opera la gracia con otras imágenes, como la «cima del alma», «el fondo del alma», la «esencia del alma», la «chispita»... Se trata de metáforas dinámicas -y no una parte del alma-, que designan la relación más profunda e íntima entre Dios y el ser humano, la participación del hombre en el ámbito divino. Por ello el mismo Eckhart parece «desdecirse» a sí mismo:

10 Eckhart, Sermón 69 Modicum et iam non videbitis me, Largier II, 44.

11 Cf. Eckhart, Del hombre noble (Von dem edeln menschen), Largier II, 314 (Vega, 115).

12 Cf. Eckhart, In Gen. I n.115, LW I, 271ss. «...cada naturaleza intelectual como tal tiene como modelo a Dios y no sólo una idea divina. [...] De ahí viene que el hombre procede de Dios 'a semejanza' de la sustancia divina, pues la naturaleza intelectual es la única capaz de recibir las perfecciones sustanciales que pertenecen en propio a la esencia divina».

13 «Tengo en mi alma una potencia que es absolutamente receptiva a Dios (diu ist gotes alzemale enpfenclich)». Eckhart, Sermón 68 Scitote, quia prope est regnum dei, Largier II, 32. Se puede tratar también del «intelecto paciente» (lîdende vernunft), frente al «intelecto agente» (würkende vernunft). Pues, según Eckhart, en la persona unida a Dios, éste se encarga de la operación y ella ha de situarse en la pasividad; así, Dios asume el papel de «intelecto agente». Cf. Sermón 104 In his quae patris mei sunt, DW IV, 570ss. 
«Algunas veces he dicho que en el espíritu hay una única potencia y sólo ella es libre. A veces he dicho que es una custodia del espíritu; otras he dicho que es una luz del espíritu y otras veces que es una centella. Pero ahora digo que no es ni esto ni lo otro, y sin embargo es algo que está por encima de esto y lo otro y por encima de lo que el cielo lo está sobre la tierra. [...] Está libre de todo nombre y desnuda de toda forma, totalmente vacía y libre, como vacío y libre es Dios en sí mismo.

[...] Dios se halla dentro, floreciendo y reverdeciendo con toda su Deidad, y el Padre engendra a su Hijo unigénito de forma tan verdadera como en sí mismo, pues verdaderamente él vive en esa potencia» $(\text { Ekhart, s. f. })^{14}$.

\section{Por el intelecto, más allá de las potencias}

Volviendo al tema que nos ocupa, puede plantearse otra pregunta: Si la felicidad del ser humano se halla en «padecer a Dios», en «la verdadera unión con Dios», ¿cómo puede esta unión tener lugar? ¿Hay alguna cosa que pueda hacer el ser humano? ¿Cómo contribuyen las facultades humanas en el encuentro con Dios que tiene lugar "ya ahora"?

En el fondo, según los dominicos alemanes, se trata de hacernos conscientes, de "perforar" la realidad y reconocer que "ahora" Dios está irrumpiendo en nuestras vidas.

«El ser humano -explica el Maestro Eckhart en sus Conversaciones de discernimiento con los novicios-, debe aprender a penetrar en las cosas y aprehender a nuestro Dios ahí dentro, y por un vigoroso esfuerzo interior, ser capaz de imprimir la imagen de Dios en su fuero íntimo, de manera sustancial. Se puede comparar con la persona que quiere aprender a escribir: está claro que si quiere lograr esta destreza, tiene que ejercitarse mucho y a menudo en esta actividad, por más penoso y difícil que le resulte o por imposible que le parezca; si está dispuesto a ejercitarse asiduamente y con frecuencia, lo aprenderá y dominará este

14 Eckhart, Sermón 2 Intravit Jesus in quoddam castellum, Largier I, 32-36 (Vega, 45). 
arte. Primero tiene que fijar sus pensamientos en cada letra individual y grabársela muy firmemente en la memoria. Pero más tarde, cuando ya domina el arte de escribir, no le hacen falta en absoluto la representación de la imagen ni la reflexión; escribe despreocupada y libremente» (Ekhart, s. f. $)^{15}$.

Por lo tanto, según Eckhart y sus discípulos, «el ser humano debe percibir [aprehender] a Dios en todas las cosas y ha de acostumbrar su corazón (gemüete) a tener siempre presente a Dios en su corazón, en su aspiración y en su amor» $(\text { Ekhart, s. f. })^{16}$. ¿Cómo lograrlo?

\section{a. Voluntad e intelecto}

Hijo de la escuela dominicana, entre las facultades humanas, Eckhart prefiere, como hemos visto poco antes, el intelecto a la voluntad, como cauce para alcanzar la felicidad. Así lo explica:

«La voluntad [y en ella, el amor] es la fuerza motriz de la actuación» -es decir, lo que nos puede conducir hacia la bienaventuranza-, pero «el intelecto es la virtud aprehensiva»; por tanto es el intelecto el que tiene la primacía, pues la bienaventuranza consiste en la aprehensión, en la unión plena con Dios (Ekhart, s. f. $)^{17}$. Sin embargo, ambos -voluntad e intelecto- están en íntima relación y nos encaminan hacia la bienaventuranza: «por el conocimiento -afirma Eckhart- concibo a Dios en mi interior, pero por el amor voy hacia Dios, (penetro en Dios)» (Ekhart, s. f. $)^{18}$. Por esto, los místicos alemanes muestran un gran aprecio hacia el amor, que nos conduce hacia Dios; pero en la mayor parte de sus textos, asocian la felicidad y bienaventuranza al conocimiento, pues por éste se alcanza una unión plena. Ya que en el acto de conocer, como en el acto de ver, el que conoce y lo conocido, el que ve y lo visto están unidos y son uno. Siguiendo a San Agustín (De Trinitate IX c.12), Eckhart explica que: «ver y ser visto son uno, [...], es decir,

15 Eckhart, Conversaciones de discernimiento (Die rede der underscheidunge) c.6, Largier II, 350 (nuestra traducción).

16 Cf. Eckhart, Conversaciones de discernimiento (Die rede der underscheidunge) c.6, Largier II, 346 (nuestra traducción).

17 Cf. Eckhart, In Ioh. n. 677, LW III, 592:1-4.

18 Eckhart, Sermón 6 Justi vivent in aeternum, Largier I, 86 (Vega, 55). «Mit bekennenne nime ich got in mich, mit minnenne gân ich in got». 
al mismo tiempo comienzan, duran, [...], al mismo tiempo se originan y mueren» $(\text { Ekhart, s. f. })^{19}$. Además, cuando lo que se conoce es a Dios, el ser humano recibe de Él todo su ser (Ekhart, s. f. $)^{20}$. Y el Maestro alemán llega a afirmar enfáticamente en un sermón que: «El ojo con el cual veo a Dios, es el mismo ojo con el cual me ve Dios; mi ojo y el de Dios son un solo ojo y una sola visión y un solo conocer y un solo amar» (Ekhart, s. f. $)^{21}$.

\section{b. Fruto de la bienaventuranza: saber y gozar de la unión}

El Maestro Eckhart clarifica esta afirmación de que el conocimiento humano es fuente de bienaventuranza y señala algunas puntualizaciones.

Así, en el sermón «Del hombre noble» (Von dem edeln menschen) el dominico alemán emplea dos imágenes, «la raíz» $\mathrm{y}$ «los frutos», para diferenciar entre la causa y origen de la bienaventuranza, y sus efectos. Indica que para algunos, la felicidad consiste en ser conscientes de que conocemos a Dios, y por tanto, que gozamos de Él.

«A algunas personas les parece, y así podemos creerlo, que en ese conocimiento reside la flor y el fruto de la bienaventuranza, en el que el espíritu conoce que conoce a Dios; pues si disfrutando de todos los bienes no lo supiera, ¿de qué me serviría y qué clase de bienes serían para mí?» (Ekhart, s. f. $)^{22}$.

En el sermón 68 constata, por ejemplo, que ciertamente, somos felices de saber que Dios está cerca de nosotros:

«El ser humano es más feliz que una piedra o una madera, porque conoce a Dios y sabe lo próximo que está de él. Y cuanto más lo sé, más feliz soy, y cuando menos consciente soy de ello, menos feliz me encuentro. No soy feliz porque Dios está en mí, porque es cercano a mí y

19 Eckhart, In Ioh. n.107, LW III, 92.

20 Cf. Eckhart, In Ioh. n.107, LW III, 92. «Por el hecho de que el hombre, como se ha dicho, recibe todo su ser del todo de Dios mismo, su objeto, ser para él no es ser por sí mismo sino ser por Dios (sed deo esse), - por Dios en tanto que principio donador de ser y para Dios en tanto que fin, para el cual es y vive-, y es ignorarse a sí mismo y a toda cosa salvo Dios y lo que es en Dios en tanto que es en Dios y que es Dios».

21 Eckhart, Sermón 12, DW I, 201 (Brugger, 364).

22 Eckhart, Del hombre noble (Von dem edeln menschen), Largier II, 328 (Vega, 121) 
lo tengo, sino porque reconozco lo cerca que está de mí y 'sé' de Dios» (Ekhart, s. f. $)^{23}$.

\section{c. Raíz de la bienaventuranza: aprehender a Dios desnudo}

Sin embargo, la raíz de la bienaventuranza se encuentra solo en «Dios desnudo», es decir, en Dios mismo, y no en que seamos conscientes de su presencia. Así lo explica el Maestro Eckhart:

«[...] lo primero en que consiste la bienaventuranza es en que el alma contempla a Dios desnudo. Ahí obtiene todo su ser y su vida y crea todo lo que ella es del fondo de Dios y nada sabe del saber, ni del amor, ni de cualquier otra cosa. [...] Allí no sabe de nada que no sea el ser y Dios. [...] Pues ciertamente, el hombre que no se conoce en absoluto a sí mismo y a las otras cosas, sino sólo a Dios, ciertamente, está allí en donde llega a ser bienaventurado y dichoso; en las raíces y el fondo de la bienaventuranza (in der wurzeln und in dem grunde der sælicheit)» $(\text { Ekhart, s. f. })^{24}$.

No se trata, por tanto, de «pensar a Dios», elaborar un concepto sobre él, sino «contemplar a Dios desnudo». Por ello, Eckhart afirma que «el ser humano no debe tener ni contentarse con un Dios pensado, pues cuando el pensamiento se desvanece, Dios se desvanece también. Debe más bien tener a Dios en su esencia -Dios presente realmente- (ein gewesenden got), que se encuentra muy por encima de los pensamientos del ser humano y de toda criatura» (Ekhart, s. f. $)^{25}$.

De ahí que la felicidad consista en conocer a Dios, pero «no desde el exterior, como cuando se perciben las cosas» (cf. Sermón alemán 94) ${ }^{26}$, sino desde el

23 Eckhart, Sermón 68, Scitote, quia prope est regnum dei, Largier II, 32-34. Hemos traducido este sermón completo en Silvia BARA BANCEL, El Reino de Dios está cerca. Dos sermones inéditos del Maestro Eckhart en castellano: (Lc 21,31) y al octavo día (Lc 2,21): EE 88 (2013) 195-206. Aquí: p. 200.

24 Eckhart, Del hombre noble (Von dem edeln menschen), Largier II, 328 (Vega, 121).

25 Eckhart, Conversaciones de discernimiento (Die rede der underscheidunge) c.6, Largier II, 448.

26 «La bienaventuranza consiste en que se conoce a Dios, no desde el exterior como cuando percibimos [las cosas]. Todo lo que conocemos desde el exterior con diferencias, no es Dios. El conocimiento de Dios es una vida que fluye a partir del ser de Dios y del alma, pues 
interior. Y en esa experiencia quedan trascendidas todas las facultades humanas ${ }^{27}$ $\mathrm{y}$, por ello, se trata más bien de un «desconocimiento o ignorancia» (unwizzen), un «conocimiento desconocido» (unbekante bekantnisse) (Ekhart, s. f.) ${ }^{28}$, una docta ignorancia, dirá más tarde Nicolás de Cusa, en donde los opuestos coinciden (expresiones que ya se hallan en Enrique Suso y en el Maestro Eckhart).

\section{d. Todo desde Dios y en Dios}

Para las personas que logran tener esta experiencia, explica Suso, «Dios ha llegado a ser todo y todas las cosas se vuelven, en cierto modo, divinas; pues todas las cosas le responden en el modo en el que son en Dios, pero al mismo tiempo cada cosa sigue siendo esto o aquello, mantiene lo que es según su esencia natural» (Suso, s. f. $)^{29}$. Perciben todo en Dios y desde Dios, incluso las dificultades y los sufrimientos, y «nada puede separarles de Dios» (Ekhart, s. f. $)^{30}$. Aquí los místicos alemanes muestran una gran dosis de humanidad y de sentido común. La profunda y constante alegría, fruto del «nacimiento de Dios en el alma» (Ekhart, s. f. $)^{31}$, no significa para ellos que haya desaparecido todo dolor, ni que se deba tener una impasibilidad o ser insensibles a la realidad. El Maestro Eckhart lo aclara en su famoso sermón sobre Marta y María:

«Os imagináis que mientras haya palabras que os conmuevan o alegren sois imperfectos. Pero no es así. Incluso con Cristo no era así; es lo

Dios y el alma tienen un ser y son uno en el ser: y todas las operaciones fluyen desde Dios pero permanecen interiores. Ahí conoce el alma a Dios, pues también es una en y con el ser de Dios. Y esta es la verdadera bienaventuranza, donde el alma tiene una vida y un ser con Dios. Y esto es el conocimiento de Dios, ahí desaparece todo otro conocimiento y ser. El alma no sabe otra cosa sino que ella se halla en Dios y Dios en ella, y en Él todas las cosas». Eckhart, Sermón 94, DW IV, 147.

27 Cf. por ejemplo: «La bienaventuranza no reside ni en el entendimiento (vernünfticheit) ni en la voluntad sino por encima de ellos: la bienaventuranza reside allí donde se halla la bienaventuranza en cuanto bienaventuranza, y no como entendimiento, y donde Dios se encuentra como Dios y el alma como imagen de Dios. Hay bienaventuranza allí donde el alma toma a Dios como es Dios». Sermón 43 Adolescens tibi dico: surge, Largier I, 466. en el 104.

28 Eckhart explica especialmente esta «ignorancia» en los sermones alemanes 101, 103 y

29 Suso, Vita c.48, 163:1-6.

30 Cf. Eckhart, Sermón 86.

31 Cf. por ejemplo, Eckhart, Sermón 76. 
que da a conocer cuando dice: "mi alma se aflige hasta la muerte" [Mt 26,38]. [...] Por eso digo que no ha habido todavía un santo, ni puede haberlo, a quien la pena no haya hecho daño o el amor alegrado». [...] sucede que un santo, al que nada puede separarlo de Dios, tenga el corazón roto; si entonces es ayudado por la gracia, su voluntad permanece simplemente en Dios y dice, Señor, te pertenezco y tú me perteneces. Sea lo que sea lo que le suceda -prosigue Eckhart- no es obstáculo para que la bienaventuranza eterna, en cuanto cima más alta del espíritu, no sea afectada, allí donde se halla unida con la voluntad siempre amada de Dios». (Ekhart, s. f.) $)^{32}$.

Precisamente aquí queda indicado un aspecto fundamental de la mística alemana: su enseñanza sobre cómo lograr la felicidad plena, que abordaremos a continuación.

\section{4. ¿Cómo? Desprendimiento}

El camino hacia la bienaventuranza, hacia el contemplar a Dios cara a cara y llegar a ser plenamente feliz, pasa por ofrecer a Dios la propia voluntad y por ponerse absolutamente en sus manos. Supone al mismo tiempo un camino hacia el silencio, o dicho de otro modo, de «despojamiento de toda imagen» (entbilden) y del "ego"; un camino de «liberación, de purificación y vaciamiento» (abgescheidenheit), o de «desprendimiento o abandono» (gelassenheit) de todo apego a cosas, personas, al propio yo e incluso del consuelo por gozar de la presencia de Dios, para «dejar a Dios por Dios», -dice Eckhart-. Y todo ello, para que Dios pueda «irrumpir» y penetrar en el fondo del alma. Pues solo puede ser recibido cuando el ser humano se hace totalmente receptivo, cuando se vacía de toda expectativa, de toda exigencia, de toda voluntad, de todos sus prejuicios, y se pone plenamente en sus manos; solo entonces puede el hombre «padecer» a Dios y ser uno con Él. Así lo explica en sus Conversaciones de discernimiento (Die rede der underscheidunge):

«Se trata de una compensación equitativa y un negocio justo: en la medida en que sales de todas las cosas, en esa medida, ni más ni menos,

32 Eckhart, Sermón 86, Vega, 110. 
entra Dios con todo lo suyo, siempre que salgas completamente de lo tuyo en todas las cosas» (Ekhart, s. f. $)^{33}$.

Y también en el Sermón 66:

«[...] cuando el ser humano se ha liberado completamente de sí mismo por amor a Dios, cuando ya no pertenece más que a Dios solo y no vive más que por Dios, es verdaderamente igual por gracia, a lo que Dios es por naturaleza, [...] pues la vida de Dios y su ser están totalmente en ese ser humano» (Ekhart, s. f. $)^{34}$.

Y ello supone la alegría más plena, la suprema bienaventuranza.

El desprendimiento, el desasimiento; por tanto, son el anverso de una moneda cuyo reverso es la unión con Dios, vivir en Él y desde Él, desde una serena y profunda alegría, en medio de lo cotidiano.

Cabe resaltar también que, para la mística dominicana, ello no supone salir físicamente del mundo, ir al desierto, o permanecer constantemente en la soledad de un monasterio; lo explica el Maestro Eckhart en sus conversaciones con los novicios:

«Me hicieron la siguiente pregunta: a muchas personas les gustaría retirarse completamente del mundo y vivir en la soledad, para encontrar allí la paz, o también quedarse en la iglesia. ¿Sería esto lo mejor? Yo he respondido: «iNo!»y ipresta atención porqué!

Quien tiene una actitud recta, se siente a gusto en todas partes y con todo el mundo. Pero el que carece de rectitud, se siente mal en todas partes y con todo el mundo. Pero aquel cuya actitud es recta, en verdad tiene a Dios con él. Aquél que posee a Dios en verdad lo posee en todo lugar y en la calle y con todo el mundo igual que en la Iglesia en la soledad o en una celda. Con tal de que lo posea rectamente, de que lo posea siempre, nadie podrá distraerle.

33 Eckhart, Conversaciones de discernimiento (Die rede der underscheidunge) c.4, Largier II, 342.

34 Eckhart, Sermón 66 Euge, serve bone et fidelis, Largier I, 10. 
¿Por qué?

Porque posee únicamente a Dios y pone sus miras sólo en Dios, y todas las cosas se vuelven para él puro Dios. Semejante hombre lleva a Dios en todas sus obras y en todos los lugares, y todas las obras de este hombre las opera solo Dios; pues, la obra pertenece más propia y verdaderamente a quien es causa de ella que a quien la ejecuta. Si concentramos, pues, nuestra vista pura y exclusivamente en Dios, en verdad Él habrá de actuar en nuestro lugar y nadie, ni la muchedumbre ni el lugar, son capaces de obstaculizar sus obras. Resulta, pues, que a tal hombre nadie le puede estorbar porque no ambiciona ni busca ni prueba nada sino Dios; porque Dios está unido a él en todas sus aspiraciones» $(\text { Ekhart, s. f. })^{35}$.

En el tratado alemán Del desasimiento, cuyo autor es, muy probablemente, el Maestro Eckhart, se pone el ejemplo siguiente, para mostrar cómo puede el "ser humano exterior" actuar, y; sin embargo, mantenerse libre y ecuánime en su interior:

«Una puerta se abre y cierra en un gozne. Ahora bien, podemos comparar la hoja externa de la puerta al hombre exterior y el gozne al hombre interior. Y cuando la puerta se abre y cierra, la hoja exterior se mueve de acá para allá pero el gozne permanece, no obstante, inmóvil en el mismo lugar y esto es la causa de que no cambie nunca. Lo mismo sucede en nuestro caso, supuesto que lo sepas entender bien» (Ekhart, s. f. $)^{36}$.

Por ello, en su sermón sobre Marta y María (Sermón 86), Eckhart considera, haciendo una interpretación original del evangelio, que es Marta la perfecta, porque está al servicio, mientras que María parece quedarse apegada al consuelo de las palabras de Jesús. En ese mismo sermón el dominico subraya que no se trata de dejar de actuar para vivir únicamente en la contemplación, sino de obrar de

35 Eckhart, Conversaciones de discernimiento (Die rede der underscheidunge) c.6, Largier II, 344-346 (nuestra traducción).

36 Eckhart, Del desasimiento (Von abegescheidenheit), Largier II, 450 (Brugger, 254). 
manera ordenada y con sabiduría: no vivir "en la preocupación" por las cosas, sino "junto a ellas", al servicio, buscando la voluntad de Dios en todo momento, como Jesús y sus discípulos y discípulas.

\section{No es difícil...}

Cabe terminar con unas palabras del Maestro Eckhart, que recuerdan que este camino hacia la bienaventuranza es un don de Dios. Él mismo nos conduce y nos atrae hacia Él, «es una obra divina, el ser humano no tiene más que padecer (lîden) a Dios y dejarle, sin resistirse», -sostiene el dominico (Ekhart, s. f.) ${ }^{37}$. Y «cada don [que recibimos] prepara la receptividad a un nuevo don y, mejor, a un don mayor -explica. Pues cada don de Dios amplía la receptividad y el deseo de acoger otro más y cada vez mayor» (Ekhart, s. f. $)^{38}$. Por ello, concluye el Maestro Eckhart en uno de sus sermones:

«Nadie debe pensar que es difícil llegar, aunque al oír hablar de ello parece grande y difícil. Bien es cierto que al principio el desprendimiento es un poco difícil, pero cuando se avanza, nunca la vida fue tan fácil, ni tan alegre, ni tan amable y Dios se emplea a fondo en permanecer constantemente cerca del hombre, en instruirlo, con el fin de conducirle, si el hombre quiere seguirle. [...] Dios está dispuesto en todo tiempo, pero nosotros estamos muy poco dispuestos. Dios está cerca, pero nosotros estamos lejos, Dios está en el interior, pero nosotros estamos fuera. Dios nos es íntimo, pero nosotros somos extranjeros. El profeta dice: ‘Dios conduce a los justos por caminos estrechos, hacia el sendero ancho, para que alcancen la amplitud y la anchura'. ¡Que Dios nos ayude para que todos le sigamos, con el fin de que nos conduzca a Él, allí donde le conoceremos verdaderamente! Amén» (Ekhart, s. f.) $)^{39}$.

37 Cf. Eckhart, Sermón 73 Dilectus deo et hominibus, Largier II, 98.

38 Cf. Eckhart, Sermón 102, DW IV, 423.

39 Eckhart, Sermón 68, Scitote, quia prope est regnum dei, Largier II, 40. 


\section{Referencias}

Bara, S. (2008). Las raíces de la felicidad, según el Maestro Eckhart. Avila: F. J. Sancho Fermín (ed.), Mística y filosofía, Cites, pp. 131-144.

Bihlmeyer, B. \& Seuse, H. (1961). Deutsche Schriften. Frankfurt: Minerva.

De Libera. A. (1999). Eckhart, Suso, Tauler y la divinización del hombre, Madrid: José J. De Olañeta.

Eckhart, M. (2008). Werke. I Predigten. II. Predigten, Traktate. Text und Kommentar, ed. Niklaus Largier (Deutscher Klassiker Verlag TB 24-25), Frankfurt: Text un Kommentar.

(2003). Die deutschen und lateinischen Werke. Die deutschen Werke IV, 1, ed. Georg Steer, Stuttgart: Kohlhammer.

(1956). Die deutschen und lateinischen Werke. Die lateinischen Werke, 5. vol., ed. de Joseph Koch et al., Stuttgart: Kohlhammer.

(2013). Obras alemanas: Tratados y Sermones. Buenos Aires: Las Cuarenta.

(2011). El fruto de la nada, ed. Amador Vega Esquerra, , Madrid: Alianza

Editorial (citado como Vega y página). Aquí: Eckhart, Sermón 101 Dum medium silentium, DW IV, 352.

Martín, J. L. (2014). Razones para la alegría. Toledo: Sígueme.

Martín, J. (1999). El fenómeno místico, estudio comparado, Madrid: Trotta.

Theglobeandmail (s. f.). En: http://www.theglobeandmail.com/news/ national/article 24073928.ece/BINARY/World+Happiness+Report.pdf. Recuperado: 11/08/15. 